\title{
Dialysis and Its Effect on Sexual Actions, Comparison of Multiple Sexual Performances in Dialysis Patients to Normal People, a Relational Design
}

\author{
Fatemeh Fayazbakhsh ${ }^{1 *}$
}

\section{ABSTRACT}

Introduction: sexual performance is one of the important aspects of the quality of life which can be effected by various illnesses, among them kidney disease can be mentioned. Purpose: this study was performed with the goal of comparing the dimensions of the sexual performance in dialysis patients and normal people. Method: The current study is a kind of causal-comparative one in the realm of descriptive studies in the year 1392 on a sample of 60 individuals $(\mathrm{N}=60)$ in the format of four groups of men dialysis patients $(n=15)$, women dialysis patients $(n=15)$, and healthy men and women (each group 15 individuals) was performed. For the purpose of choosing the subjects the method of multi-stage cluster sampling was used, also to choose the control group with attention to the consistency factor first degree relatives of the patients were used. With attention to the nature of the study the method of gathering of the data was done by survey and to gather information questionnaires on erection function (IIEF, rate of responding=91\%) and the questionnaire of the women's sexual function (FSFI, rate of responding $=89 \%$ ) was used. Also the quality datas resulting from the coding demographic evaluations and with the assistance of the quality datas analysis tools of Atlas TI 5,2 were analyzed. Findings: the results of the study showed that between the group of healthy women and dialytic women because of the variables related to the sexual performance, there is no meaningful difference ( $>>0 / 171$ ), but between the healthy men and dialytic men with respect to dimensions of the mentioned variables meaningful difference was seen $(p<0 / 0001)$. Conclusions: the findings of this study makes evident the need for psychological follow-ups and preparing the needed means for increasing the quality of this group of the society is evident more than before.

Keywords: Sexual Performance, Dialytic Patients, Erection Problem, Sexual Satisfaction, Hem dialysis.

\footnotetext{
${ }^{1}$ M.A in Clinical Psychology, Semnan Islamic Azad University Branch, Semnan, Iran *Responding Author (C) 2016 I F Fayazbakhsh; licensee IJIP. This is an Open Access Research distributed under the terms of the Creative Commons Attribution License (http://creativecommons.org/licenses/by/2.0), which permits unrestricted use, distribution, and reproduction in any Medium, provided the original work is properly cited.
} 


\section{Dialysis and Its Effect on Sexual Actions, Comparison of Multiple Sexual Performances in Dialysis Patients to Normal People, a Relational Design}

Sexual performance is one of the important aspects of life quality. Studies have shown that various problems in the mentioned performances is known as a factor that effects life quality and in fact evaluation of sexual performance, plays an important role in the studies related with the quality of life. The World Health Organization, acknowledges sexual health as unity and coordination between mind, feelings and body which recognizes the social and mental aspects of the human as giving rise to its personality and leads to relation and love. Hence any disturbance that leads to discoordination and as a result lack of satisfaction from the sexual relation, it can lead to sexual performance problem along with it (Jahanfar \& Molae nezhad, 2000). Proper and healthy sexual performance is one of the indicators of healthy body and mind which causes common enjoying feelings between the couples and increases the individual's ability to have more efficient encounter with stresses and life problems (Teimorpour et al, 2009). Sexual performance can be discussed from different aspects to mention are the condition of erection of genitals, condition of ejaculatory semen, sexual desire and the time lapse of sexual closeness in which any of them by themselves or together may become problematic in an individual. Also women's sexual performance dysfunctions for example decreased sexual desire, pain during intercourse and or problems related to orgasm have been multi-factorial and is effected by the physical condition of the sexual organs and social factors and mental-psychological factors. The rate of prevalence of the dysfunction in women's sexual performance in the world is between 26$50 \%$ and in Iran about 39/5\% (Achtari \& Dwyer, 2005). Sexual performance dysfunction may be caused from many factors. Some of these factors are: individual's general health condition, diabetic disease, ardiovascular diseases, genitourinary system diseases and kidney diseases (Salehzade et al, 2010).

Often kidney failure and its treatment effects the patient's sexual desire and its ability to enjoy it (Feress, 1994). About 50 percent of the patients with chronic kidney failure have problems in sexual performance. The intensity of this problem can be in the range of a slight decrease in sexual desire to lack of sexual satisfaction. On the other hand having stress in these patients can to some extent cause problem in the couple's relationship. Usually these patients lose their selfconfidence and have a negative viewpoint towards their body (Safarinezhad, 2011). Therefore $33 \%$ of the patients with chronic kidney failure lack marriage relationship and $44 \%$ of them have relationship only once a week. About 40-80 percent of patients on dialysis, have sexual disability. On the other hand the most important factor of sexual disability in men with chronic kidney failure, is disorder in pelvic vessels. In kidney chronic failure not only the rate of blood circulation into the genitals will have problem, but also the patient will have vessel leakage also. About 60 percent of the cause of sexual disability in men with normal kidneys is these vascular factors (Safarinezhad, 2011). Also hemodialysis has many complications along with it: one of these complications is changes in menstruation or its complete stop in women and sexual disability and sterility in men (Feress, 2001). In United States 10-30 million people have sexual disability from which $82 \%$ is seen in patients under hemodialysis (Hasanzadeh et al, 2010). With considering what was mentioned and with attention to the importance of sexual 


\section{Dialysis and Its Effect on Sexual Actions, Comparison of Multiple Sexual Performances in Dialysis Patients to Normal People, a Relational Design}

performance parallel to the other components of the psychological health and also existence of contradictory findings specially in the existence of performance differences in patients with kidney failure, in this study we intend to compare these performances in kidney patients with a sample of normal people.

\section{METHOD}

This study has a comparison plan and is in the format of descriptive studies. The statistical population of the research is composed of the patients of the city of Eshtehard. For this reason and in the format of multi-stage cluster sampling, two hospitals from this city were chosen and from each hospital 15 testable were chosen and the other half of the testable were formed by the patients' relatives such that for the reasons of demography variables had the highest rate of replicating. The criterion for the entrance and exit of the testable were evaluated carefully. The criterion for entrance were 1) to have chronic kidney disease in the format of having a history of more than two years of the mentioned indications, 2) having the ability to read and write, 3) range of ages from 18 to 35 years, 4) married, also the criterion for exit were: 1) having psychological problems and 2) using psychological complementary treatments. After evaluation of the mentioned criterion and performing structural clinical interview, the testable with attention to observation of ethical standards entered the study. Knowledgeable acceptance in this study was without any coercion, threat, bribery and seduction and to the refusal of individuals from acceptance or continued participation in the study was respected. It was tried that the methods of research to be compatible with cultural and ethical standards of the testable and the performance of the research not to damage or pause in the process of physicians care of the testable. The main body of the data gathered relied on the method of paper and pen. For this purpose and with the goal of evaluation of the index of sexual performance a questionnaire with this name was used and the data mentioned was analyzed with the assistance of a parametric test, covariance and variance were evaluated and analyzed.

\section{Instruments}

The questionnaire on the function of erection (IIEF): This questionnaire has been designed by Rosen and et.al (1997) with the goal of measuring, sexual desire, performing the activity and satisfaction from the designed sexual activity and consists of 15 articles and evaluates 5 general topics, the mentioned topics are performance of erection, performance of orgasm, sexual desire, satisfying intercourse and satisfying sexual performance in general. At present this questionnaire is used in most points of the world (Wein et al, 2007). Reliability of the questionnaire in the present study was calculated using Cronbach's alpha method to be 0/86.

The women's sexual performance questionnaire (FSFI): this scale has been designed by Rosen and et al (2000). The women's sexual performance questionnaire is short which covers main areas of sexual performance and it is used for the purpose of clinical and nonclinical populations. This questionnaire covers 19 articles and evaluates the women's sexual performance in the six 


\section{Dialysis and Its Effect on Sexual Actions, Comparison of Multiple Sexual Performances in Dialysis Patients to Normal People, a Relational Design}

areas of desire, psychological stimulation, humidity, orgasm, satisfaction and sexual pain and in a group of women it is validated by sexual stimulation disorder. The mentioned questionnaire has been used outside of the country in many studies and has shown a high degree of internal consistency and reliability, also in the frame of differential validity, it has shown meaningful difference between the scores of the group of patients and control group. With regards to the high scores and for the reason of shortness of the questionnaire it appears that the index of women's sexual performance to be a proper tool in evaluation of the sexual performance. In Iran the scale of women's sexual performance has been normalized by Mohammadi and et. al (1387).

\section{RESULTS}

The findings resulting from the decomposition and analysis of the data in two parts of descriptive (central indices) and inferential (test of analysis of variance and analysis of covariance of multivariable and uni-variable) with the assistance of the statistical software of SPSS version 19 have been analyzed and shown in the table below.

\section{Average and standard deviation}

In table 1, score of testables in the frame of indices of average, standard deviation, minimum and maximum score are presented.

Table 1: descriptive indices of variables of men and women's sexual performance

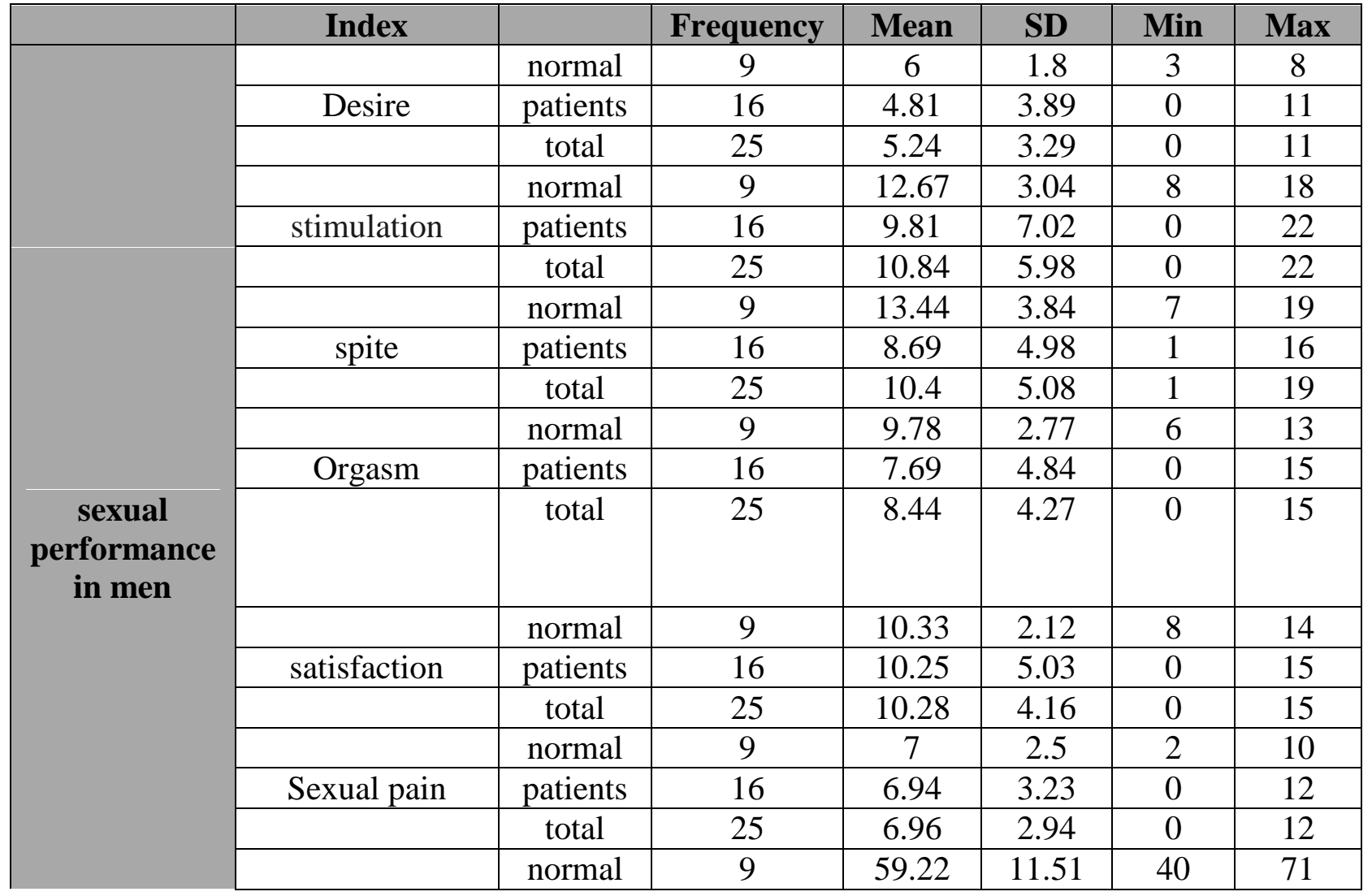


Dialysis and Its Effect on Sexual Actions, Comparison of Multiple Sexual Performances in Dialysis Patients to Normal People, a Relational Design

\begin{tabular}{|c|c|c|c|c|c|c|c|}
\hline & $\begin{array}{c}\text { sexual } \\
\text { performance(F) }\end{array}$ & patients & 16 & 48.19 & 24.89 & 2 & 81 \\
\hline \multirow{19}{*}{$\begin{array}{c}\text { sexual } \\
\text { performance } \\
\text { in women }\end{array}$} & & total & 25 & 52.16 & 21.46 & 2 & 81 \\
\hline & & normal & 21 & 81.21 & 3.2 & 15 & 27 \\
\hline & $\begin{array}{l}\text { Erection } \\
\text { function }\end{array}$ & patients & 14 & 15.43 & 4.69 & 6 & 23 \\
\hline & & total & 35 & 19.26 & 4.95 & 6 & 27 \\
\hline & & normal & 21 & 9 & 1.52 & 5 & 10 \\
\hline & Orgasm & patients & 14 & 5.86 & 2.66 & 0 & 10 \\
\hline & & total & 35 & 7.74 & 2.55 & 0 & 10 \\
\hline & & normal & 21 & 7.14 & 1.74 & 4 & 10 \\
\hline & Desire & patients & 14 & 5.07 & 1.9 & 2 & 8 \\
\hline & & total & 35 & 6.31 & 2.05 & 2 & 10 \\
\hline & & normal & 21 & 11.86 & 1.28 & 10 & 14 \\
\hline & satisfaction & patients & 14 & 9.64 & 1.86 & 5 & 13 \\
\hline & & total & 35 & 10.97 & 1.87 & 5 & 14 \\
\hline & & normal & 21 & 9 & 1.55 & 5 & 10 \\
\hline & $\begin{array}{c}\text { Total } \\
\text { satisfaction }\end{array}$ & patients & 14 & 6.36 & 2.71 & 2 & 10 \\
\hline & & total & 35 & 7.94 & 2.44 & 2 & 10 \\
\hline & & normal & 21 & 58.81 & 7.18 & 44 & 70 \\
\hline & $\begin{array}{c}\text { sexual } \\
\text { performance(M) }\end{array}$ & patients & 14 & 42.36 & 12.62 & 15 & 60 \\
\hline & & total & 35 & 52.23 & 12.57 & 15 & 70 \\
\hline
\end{tabular}

The findings of table 1 shows that the rate of women's sexual performance in the control group $(59 / 22)$ is higher than the average score of dialytic patients (48/19). Also the results show that men's sexual performance in the control group (58/81) is higher than the average score of dialytic patients (42/36).

\section{Normal distribution of the study's variables}

As you are aware one of the preconditions of using parametric statistical tests, is the normal distribution of the variables under evaluation, therefore in this study to assess the considered assumptions Kolmogorov -Smirnov test was used which the results are shown in table 2.

Table 2: The test of assuming normal distribution of the variables,

\begin{tabular}{|c|c|c|}
\hline Index & Kolmogorov -Smirnov & Sig. \\
\hline Quality of life & 0.71 & 0.68 \\
\hline Sexual desire & 0.62 & 0.82 \\
\hline women's sexual performance & 0.72 & 0.55 \\
\hline men's sexual performance & 0.96 & 0.30 \\
\hline
\end{tabular}




\section{Dialysis and Its Effect on Sexual Actions, Comparison of Multiple Sexual Performances in Dialysis Patients to Normal People, a Relational Design}

As is deduced from the findings in table 2, a meaningful level is observed in the variables under evaluation more than the amount of the criteria 0/05 therefore we can acknowledge that the distribution of the variables under evaluation in the statistical sample has a normal distribution, therefore using parametric tests are permitted.

\section{Evaluation of the equality of the variances}

As you know one of the preconditions of using the statistical test of variance analysis, is the lack of meaningfulness of the presumption of Leven in the indices under evaluation $(\mathrm{p}<0.05)$.

\section{Analysis of the covariance of the two groups}

For the purpose of comparison of the sexual multiple performances in two groups of healthy and dialytic women, the parametric test of covariance analysis was used in which the results are shown in table 4.

Table 4: Multi variable variance analysis for the means of comparison of sexual performance in two groups of healthy and dialytic men.

\begin{tabular}{|c|c|c|c|c|c|c|}
\hline $\begin{array}{c}\text { Test } \\
\text { variables }\end{array}$ & Amount & F & Df & Df error & Sig. & $\begin{array}{c}\text { Size } \\
\text { effect }\end{array}$ \\
\hline $\begin{array}{c}\text { Pilly effect } \\
\text { (state) }\end{array}$ & 0.49 & 45.02 & 6 & 17 & 0.000 & 1.000 \\
\hline $\begin{array}{c}\text { Lombodi } \\
\text { vilex }\end{array}$ & 0.05 & 45.02 & 6 & 17 & 0.000 & 1.000 \\
\hline $\begin{array}{c}\text { Hotlink } \\
\text { Effect }\end{array}$ & 15.89 & 45.02 & 6 & 17 & 0.000 & 1.000 \\
\hline $\begin{array}{c}\text { Largest } \\
\text { root }\end{array}$ & 15.89 & 45.02 & 6 & 17 & 0.000 & 1.000 \\
\hline $\begin{array}{c}\text { Pilly effect } \\
\text { (age) }\end{array}$ & 0.823 & 13.13 & 6 & 17 & 0.000 & 1.000 \\
\hline $\begin{array}{c}\text { Lombodi } \\
\text { vilex }\end{array}$ & 0.177 & 13.13 & 6 & 17 & 0.000 & 1.000 \\
\hline $\begin{array}{c}\text { Hotlink } \\
\text { Effect }\end{array}$ & 4.63 & 13.13 & 6 & 17 & 0.000 & 1.000 \\
\hline $\begin{array}{c}\text { Largest } \\
\text { root }\end{array}$ & 4.63 & 13.13 & 6 & 17 & 0.000 & 1.000 \\
\hline $\begin{array}{c}\text { Pilly effect } \\
\text { (group) }\end{array}$ & 0.38 & 1.74 & 6 & 17 & 0.171 & 0.496 \\
\hline $\begin{array}{c}\text { Lombodi } \\
\text { vilex }\end{array}$ & 0.61 & 1.74 & 6 & 17 & 0.171 & 0.496 \\
\hline $\begin{array}{c}\text { Hotlink } \\
\text { Effect }\end{array}$ & 0.61 & 1.74 & 6 & 17 & 0.171 & 0.496 \\
\hline $\begin{array}{c}\text { Largest } \\
\text { root }\end{array}$ & 0.61 & 1.74 & 6 & 17 & 0.171 & 0.496 \\
\hline
\end{tabular}




\section{Dialysis and Its Effect on Sexual Actions, Comparison of Multiple Sexual Performances in Dialysis Patients to Normal People, a Relational Design}

The effects on the basis of the results of multi variable covariance analysis test and the index of Wilkes lambda, between the groups of healthy and dialytic women in terms of sexual performance variables there is no meaningful difference.

Analysis of variance of scores in two groups of me

Table 5: Multi variable covariance analysis for the purpose of comparison of sexual performance in two groups of healthy and dialytic women

\begin{tabular}{|c|c|c|c|c|c|c|}
\hline $\begin{array}{c}\text { Test } \\
\text { variables }\end{array}$ & Amount & F & Df & Df error & Sig. & $\begin{array}{c}\text { Size } \\
\text { effect }\end{array}$ \\
\hline $\begin{array}{c}\text { Pilly effect } \\
\text { (state) }\end{array}$ & 0.98 & 381.09 & 5 & 29 & 0.000 & 1.000 \\
\hline $\begin{array}{c}\text { Lombodi } \\
\text { vilex }\end{array}$ & 0.01 & 381.09 & 5 & 29 & 0.000 & 1.000 \\
\hline $\begin{array}{c}\text { Hotlink } \\
\text { Effect }\end{array}$ & 65.70 & 381.09 & 5 & 29 & 0.000 & 1.000 \\
\hline $\begin{array}{c}\text { Largest } \\
\text { root }\end{array}$ & 65.70 & 381.09 & 5 & 29 & 0.000 & 1.000 \\
\hline $\begin{array}{c}\text { Pilly effect } \\
\text { (group) }\end{array}$ & 0.49 & 5.59 & 5 & 29 & 0.001 & 0.976 \\
\hline $\begin{array}{c}\text { Lombodi } \\
\text { vilex }\end{array}$ & 0.50 & 5.59 & 5 & 29 & 0.001 & 0.976 \\
\hline $\begin{array}{c}\text { Hotlink } \\
\text { Effect }\end{array}$ & 0.96 & 5.59 & 5 & 29 & 0.001 & 0.976 \\
\hline $\begin{array}{c}\text { Largest } \\
\text { root }\end{array}$ & 0.96 & 5.59 & 5 & 29 & 0.001 & 0.976 \\
\hline
\end{tabular}

On the basis of the results of multi variable covariance analysis and the index of Lombodi vilex, between the groups of healthy and dialytic men according to variables of sexual performance a meaningful difference exists.

\section{Uni-variable variance analysis}

Table 5: Uni-variable variance analysis for the means of comparison of sexual performance in two groups of healthy and dialytic men

\begin{tabular}{|c|c|c|c|c|c|}
\hline Index & SS & df & MS & F & Sig. \\
\hline $\begin{array}{c}\text { erection } \\
\text { function }\end{array}$ & 34.09 & 1 & 34.09 & 23.00 & 0.000 \\
\hline $\begin{array}{c}\text { peak of sexual } \\
\text { pleasure }\end{array}$ & 82.97 & 1 & 82.97 & 19.88 & 0.000 \\
\hline Desire & 36.04 & 1 & 36.04 & 11.06 & 0.000 \\
\hline satisfaction & 41.18 & 1 & 41.18 & 17.47 & 0.000 \\
\hline $\begin{array}{c}\text { Total } \\
\text { satisfaction }\end{array}$ & 58.67 & 1 & 58.67 & 13.51 & 0.000 \\
\hline $\begin{array}{c}\text { men's physical } \\
\text { performance }\end{array}$ & 2273.79 & 1 & 2273.79 & 24.18 & 0.000 \\
\hline
\end{tabular}




\section{Dialysis and Its Effect on Sexual Actions, Comparison of Multiple Sexual Performances in Dialysis Patients to Normal People, a Relational Design}

With attention to table 6 between the average of erection function in healthy and dialytic men a meaningful difference is observed. Also between the average of the peak of sexual pleasure in healthy and dialytic men a meaningful difference exists. In regards to the component of sexual desire, with attention to the amount of $\mathrm{F}$ calculated (11/064) in a meaningful level $(0 / 002)$ between the average sexual desire of healthy and dialytic men a meaningful difference exists. In regards to the component of satisfaction of sexual contact, with attention to the amount of $\mathrm{F}$ calculated (17/473) in a meaningful level $(0 / 000)$ between the average satisfaction of sexual contact of healthy and dialytic men a meaningful difference exists. About the component of comprehensive satisfaction, with attention to the amount of $F$ calculated (13/519) in a meaningful level (0/001) between the comprehensive average satisfaction of healthy and dialytic men a meaningful difference exists. With respect to the component of men's physical performance, with attention to the amount of F calculated (24/185) in a meaningful level (0/000) between the average of physical performance of healthy and dialytic men a meaningful difference exists. With attention to the mentioned results between sexual performance along with its components in dialytic men patients and healthy people a meaningful difference exists.

\section{DISCUSSION}

The study under view with the goal of evaluation of the multiple aspects of sexual performance in women and men suffering and not suffering from kidney disease was performed. The results of the present study showed that in terms of sexual performances between suffering and not suffering men from kidney disease a meaningful difference exists. Therefore and in line with the mentioned findings Diayez et al (2006) realized that sexual dysfunction is a common problem in men patients suffering from uremia. Also in the study of Ahmadvand et al (2013) it was shown that the majority of the hemodialytic patients suffer from sexual performance disorder. Such that the prevalence of sexual disability in dialytic patients is $92 / 5 \%$ from which $61 / 5 \%$ has been from the severe case. $7 / 4 \%$ did not have a problem in terms of sexual performance, $70 / 2 \%$ had decrease in sexual desire, 45/27\% had lack of ejaculation, 33/1\% had early ejaculation and 5/4\% had late ejaculation. In this study between the demographic factors for example age, the length of time of dialysis, diabetes, depression, smoking, sequence of dialysis, cause of occurrence of kidney failure, using medication and high blood pressure with sexual disability a meaningful statistical relation was observed.

In the research of Rezakhanis and Safarinejad (2005) under the title of evaluation of the abundance of types of sexual disorder and related factors in men patients referred to the Urology Hospital Clinic of 501, early ejaculation had the most abundance. Also erection problem and sexual desire problem have more effectiveness from psychological problems compared to the other problems including early ejaculation. It can be said that prevalence of contact, social, psychological and medical problems between dialytic patients lead to changes in their sexual desire and sexual performance. Medical problems like hormonal changes, anemia, use of drugs and ...psychological problems like anxiety, conformity with illness, depression and anger, body 


\section{Dialysis and Its Effect on Sexual Actions, Comparison of Multiple Sexual Performances in Dialysis Patients to Normal People, a Relational Design}

image and low self- esteem because of the changes caused in the patient body for example existence of fistula and catheter can cause lack of feeling of sexual attraction in the patient and have a negative effect on his performance. On the other hand part of the findings of this study showed that between the group of healthy and dialytic women regarding variables related to sexual performance does not have a meaningful difference from the control. The mentioned findings are in line with the research of Boss and et.al (2012). Boss and et. al (2012) showed that hemodialysis is effective on the sexual life of women above the age of sixty.

This is such that the majority of the dialytic women participating in the present research were under the age of sixty and in the range of 30-50 years. In the research of Moor and et. $\mathrm{al}^{2}$ with the title of performance, activity and sexual satisfaction in between the women getting hemodialysis which was conducted on a sample composed of 125 subjects, the results showed that a small number of women patients suffered sexual difficulty and sexual dysfunction was rare in this sample. Also the research of Boss and et. $\mathrm{al}^{3}$ with the title of the effect of nighttime hemodialysis on the sexual performance showed that difference in the sexual performances between the two groups of patient and control was not observed.

In findings not in line, Sung and et al (2008) with the title of sexual performance and life quality in Korean women suffering from chronic kidney failure receiving hemodialysis showed that the degree of menopause between the groups was different. Also the level of estradiol and testosterone was high and the level of prolactin and FSH was lower than the control group. The scores of all the dimensions of sexual performance in the group of patients specially desire, motivation, slipperyness of the vagina, peak of sexual pleasure, satisfaction and sexual pain was meaningfully less than the control group.

Also the findings of the present study was in contrast with the researches of Markus and et al (2006), Pang and et al (2005) and Sung and et al (2008). The studies mentioned reported the decrease in the levels of sexual performances in women suffering from the kidney disease to be meaningful. Maybe the reason for this difference is that in the study of Sung and et. al (2008) hormonal disorder and early menopause in the Korean women suffering from CRF receiving hemodialysis is common and because of early menopause their sexual performance is lower than the normal group. Although the women under study in the present research most were in the range of age of 30-50 years which seems that in these individuals menopause has not occurred. In another study of Pang and et al (2005) it was shown that sexual dysfunction is common in the women patients suffering from hemodialysis. The present research was done with the goal of evaluating the differences in the women's sexual performances and the men suffering and not suffering from the kidney disease. The findings showed that between the men's sexual performances in the two group of suffering and not suffering from kidney disease there is a

\footnotetext{
${ }^{2}$ Mor and et. al, 2014.

${ }^{3}$ Boss and et. al, 2012.
} 


\section{Dialysis and Its Effect on Sexual Actions, Comparison of Multiple Sexual Performances in Dialysis Patients to Normal People, a Relational Design}

meaningful difference but these differences was not seen in the women's group. The mentioned findings can be valuable in the planning of preventive models in this area.

\section{RESEARCH SUGGESTIONS}

With attention to the findings of the present research it is suggested that measures be taken to improve life quality and decrease the negative effects of the factors effecting it. Therefore attention to the stressful factors in the life of dialytic patients is of very important points which can lead to the increase in the quality of life. The sectional being of the present research makes the possibility of comprehensive explanations problematic. Also adding the evaluation form of the life quality of chronic patients as one of the forms of the medical records of the patients should be considered.

\section{LIMITATIONS}

This study in the process of performance was along with many limitations, these limitations consist of: 1) of the limitations of this study we can refer to the lack of cooperation of some of the participants, also one of the conditions of the study, was the entrance of volunteer patients, hence a number of patients did not participate in the study. 2) the hemodialysis patients because of repeated returns to the hospital did not have the desire to allow extra time for the purpose of completing the questionnaire and therefore to prevent waste of time and attracting their cooperation more, the questionnaires were completed at the same time of performing the act of hemodialysis.

\section{Acknowledgments}

The author appreciates all those who participated in the study and helped to facilitate the research process.

\section{Conflict of Interests}

The author declared no conflict of interests.

\section{REFERENCES}

Ahmadvand, Afshin, Sepehrmanesh, Zahra, Akasheh, Goudarz and Saii, Rezvan (1393). Evaluation of the sexual performance problems in the hemodialytic patients of the kashan Akhavan Hospital in the year of 1392, the journal of the University of Medical Sciences of Qom, eighth review, number 2, 20-27.

Hassanzadeh, Kamaledin; Behlooli, Abolfazl; Hajir, Samad; Ahmadi asr Badr, yeda.. and Veghari, Saman (1385). The various forms of sexual performance in dialytic patients. The medical journal of The University of Medical Sciences of Tabriz, 28(2), 45-48. Jahanfar, Shayesteh and Molainejad, mitra (1380). Study of sexual problems, Tehran: Bijeh. Rezakhaniha, Bijan and Safarinejad, Mohammad Reza (1385). Evaluation of the abundance of sexual problem types and related factors in men patients referred to the clinic of urology 


\section{Dialysis and Its Effect on Sexual Actions, Comparison of Multiple Sexual Performances in Dialysis Patients to Normal People, a Relational Design}

of the Artesh 501 Hospital in the years 1383-1384. The scientific journal of the University of the Medical Sciences of the army of the Islamic Republic of Iran. 4(4). 1041-1045.

Safarinejad, Mohammad Reza. (Bahman, 1391). The marriage relationship and chronic kidney failure. Journal of salamat. 10(409)

Salehzadeh, Maryam; Kajbaf, Mohammad Bagher; Molavi, Hossein and Zolfaghari, Massoumeh. (1390). The effectiveness of the cognitive behavioral treatment on the rate of women's sexual problems. Psychological studies of the University of Al Zahra, 7(1), 11-31.

Teymourpoor, Negar; Moshtagh, Nahaleh and Pourshahbaz, Abass. (1389). The relation of attachment styles, marriage satisfaction and feelings of sexual guilt with sexual desire in women, the journal of clinical psychology, 2(3), 1-14.

How to cite this article: F Fayazbakhsh (2016), Dialysis and Its Effect on Sexual Actions, Comparison of Multiple Sexual Performances in Dialysis Patients to Normal People, a Relational Design, International Journal of Indian Psychology, Volume 3, Issue 3, No. 5, DIP: $18.01 .093 / 20160303$ 